\title{
Economics
}

The Open-Access, Open-Assessment E-Journal

Vol. 12, 2018-43 | June 29, 2018 | http://dx.doi.org/10.5018/economics-ejournal.ja.2018-43

\section{Subjective well-being and income: a compromise between Easterlin paradox and its critiques}

\author{
Rusen Yasar
}

\begin{abstract}
Despite rising popularity of subjective well-being (SWB) as a proxy for utility, its relationship with income is still unresolved. Against the background of debates around the 'Easterlin paradox', this paper seeks a compromise between two positions: one that insists on individual relative income, and one that finds similarity between individual and aggregate levels. Proposing a model which puts the emphasis on the interaction between individual and aggregate-level factors, it argues that the effect of relative income on SWB varies across countries as a function of average income, in addition to a relatively small direct effect of the latter, in partial agreement with the two major positions. The model is tested crosssectionally on the data from the latest wave of World Values Survey. The results from hierarchical mixed-effect models confirm the main argument. But further examination reveals that there is still unaccounted variation especially in middle-income economies.
\end{abstract}

JEL D31 C31

Keywords Subjective well-being; Easterlin paradox; relative income; national income

\section{Authors}

Rusen Yasar, University of Konstanz, Germany, rusen.yasar@uni-konstanz.de

Citation Rusen Yasar (2018). Subjective well-being and income: a compromise between Easterlin paradox and its critiques. Economics: The Open-Access, Open-Assessment E-Journal, 12 (2018-43): 1-23. http://dx.doi.org/10.5018/economics- ejournal.ja.2018-43 


\section{Introduction}

The rising popularity of subjective well-being (henceforth SWB) or happiness constitutes both a continuity with and a departure from mainstream economics. On the one hand, SWB studies usually take this measure as a proxy for individual utility and thus remain within the utilitarian paradigm (e.g. Kahneman et al., 1997). On the other hand, the same perspective also takes SWB as a distinct measure of utility, and a better alternative than those conventionally endorsed in mainstream economics. Namely, when it is accepted that there are inherent limits on human cognition, hence the rationality of individual, it is no longer possible to assume that agents will make the best use of their income to maximize utility, nor that their consumption patterns reveal their utility-maximizing preferences (Kahneman, 1994; Kahneman et al., 2004). Therefore, the utility predicted at the time of a decision is not necessarily experienced by the outcome of this decision (Kahneman and Krueger, 2006; Kahneman and Thaler, 2006). Similarly, income may not be directly translated into well-being, and when it does, this may be due to a self-fulfilling belief focused on money as the ultimate indicator of achievement (Kahneman et al., 2006).

In this respect, a pressing question for economics has become one that many people ask themselves in their daily lives: does money buy happiness? And if money does buy happiness, is this simply because money is the main basis of social comparisons or it also has some intrinsic value which can be translated into well-being? The divergent answers to these questions can be grouped into two. The first group argue that the relationship between income and SWB reflects the happiness or satisfaction derived from one's relative position in society. This argument serves as the main explanation for the 'Easterlin paradox', according to which the relationship between income and SWB can be observed at the individual level of analysis, but not at the aggregate level. The second group argue that average SWB is also linked to average income. The cases of non-rising SWB despite rising income can be explained through certain qualifications, such as diminishing marginal returns, a satiation point, contextual factors or measurement issues, yet the overall pattern does not have to be radically different between individual and aggregate levels. Although this disagreement can be understood as a result of different empirical foci, this paper seeks to find an additional explanation which can serve as a compromise between the two positions.

Based on the insights offered by the first group, it is accepted here that the relativity of income positions has an autonomous influence on SWB. But, following the second group, the extent of such an autonomous influence should be partially determined by the average level of income in each society, while the latter can also have a relatively small direct effect. Thus, it will be argued that the effect of average income can be observed as both direct and mediated through the relationship of relative income with SWB. More specifically, the association between relative income and SWB is more significant at lower levels of economic development and less significant at higher levels. Although this partially results from the overarching fact of diminishing marginal returns, the effect of relative income tends to be stronger than this overall pattern, due to the autonomous influence of one's relative position in society. The next two sections will unpack the main debate in the literature and develop the main argument in relation to opposing positions. The third section will present the empirical strategy to test the argument through mixed-effect linear modelling. The fourth section will discuss the selection of data and variables to apply the specified 
models. The fifth section will summarize the findings of the analysis. Finally, the sixth section will discuss how well these findings confirm the argument.

\section{Background}

There is little disagreement on whether income is related to SWB; the answer is almost always yes in one form or another. The main point of contention is rather when, how and why income matters. It is arguably compatible with common sense to say that income always brings wellbeing, irrespectively of whether we are talking about an affluent individual or a society which is economically developed, because similarly rational individuals will translate the opportunities created by higher income into higher levels of well-being. However, as the above introductory statements highlighted, it is difficult to sustain this view once the rationality assumption is dropped. Indeed, since the first publication of what has come to be known as 'Easterlin paradox' (Easterlin, 1974), the benchmark has been the view that there is no universal direct link between income and well-being. What makes Easterlin's hypothesis a 'paradox' is the claim that income-SWB link exists at the individual level, but is not observed at the aggregate level; in other words, individuals derive happiness from higher income, but the economic growth of a society does not increase the overall or average happiness (Easterlin, 1974, 1995).

Although this observation has been labelled as a paradox, the relativity of income positions and changing aspirations have served as the standard explanation from the beginning. Focusing on relativity or income comparisons, it can be argued that agents derive their well-being by comparing their status to certain reference points in society, which change as a function of the societal level of economic development, and an increase in their individual income proportional to the increase in that reference will not contribute to their well-being (Clark et al., 2008). In the same vein, the individual behaviour can be understood in terms of the effect of increased income being offset by changing aspirations which concomitantly become more difficult to satisfy (Easterlin, 2001). Easterlin also notes that this explanation conforms to the challenge posed by Kahneman's framework, as discussed above, in the sense that the predicted utility of increased income does not translate into experienced utility, since the utility function is reshaped by more demanding aspirations (Easterlin, 2001). Further studies which look more closely at the psychological aspects (e.g. Proto and Rustichini, 2013) also confirm the role of aspirations in shaping the relationship between income and SWB.

Although the reference for such aspirations is not actually fixed for a whole country but varies according to the socio-economic characteristics of each individual, the level of economic development or the average income of a country remains the main focus of economic analyses. In this sense, other pieces of evidence which suggest that higher levels of average income do indeed increase average well-being should not be ignored. First of all, cross-sectional studies consistently find a positive association, adding another layer of puzzle to Easterlin paradox: a contrast, or at least a dissimilarity, not only between individual-level cross-sectional patterns and aggregatelevel longitudinal patterns, but also between aggregate-level cross-sectional and aggregate-level longitudinal patterns. Although this relationship is weaker at the higher levels of average income, a log-linear pattern is quite apparent (Deaton, 2008). Second, some findings also challenge 
Easterlin's longitudinal argument, claiming that economic growth brings happiness, strongly in the short run and moderately in the long run (Hagerty and Veenhoven, 2003). In this respect, the disagreement between Easterlin and his critics is usually centred on the specificities of the data used in the analysis, such as case selection, ommission of available data, comparability, measurement and too much focus on the short term (Easterlin, 2005b; Easterlin, 2017; Cf. Veenhoven and Hagerty, 2006). Third, non-rising average SWB can be attributed to the particular features of relatively affluent societies, as they passed a satiation point of basic needs, beyond which absolute levels of income matter very little (Di Tella and MacCulloch, 2010). While this can be seen as an implication of diminishing marginal returns, Easterlin (2005a) is also sceptical about the claim that marginal returns can serve as an explanation for the insignificant relationship at the aggregate level. In general, although cross-sectional comparisons return positive results in a log-linear pattern, this provides 'a questionable basis for inferring change over time' (Easterlin and Sawangfa, 2010, p. 190).

In a comprehensive reassessment of the Easterlin hypothesis, Stevenson and Wolfers (2008) find similar patterns for within-country and across-country relationships of income and happiness, and a positive association between economic growth and rising happiness; they thus argue that both cross-sectional and longitudinal analyses point to the same conclusion and a universal pattern. In order to challenge the Easterlin hypothesis on the longitudinal front, they also draw on a detailed examination of the data commonly used to support it. In this respect, Japan constitutes a crucial case, because its non-rising average SWB can be observed over a period encompassing a wide array of economic development levels, not limited to its high-income phase. However, according to Stevenson and Wolfers (2008), changing survey questions are responsible for the failure to measure increasing SWB, and for each formulation of the question, there is indeed a positive relationship with growing economy in the corresponding time period (pp. 46-56). While there are many cases that they present to support this positive relationship, Easterlin and Sawangfa (2010) find their evidence unsatisfactory due to a failure to take into account the differences between short-term and long-term relationships.

Given the diversity of arguments and findings in favour of and against the Easterlin hypothesis, it is difficult to disregard either side of the literature. Indeed, they may both be correct despite the consistent disagreements, since the divergent conclusions result from, at least partially, from choices regarding the selection of data, methods and operationalization of variables (Graham, 2011). In this sense, it is not a coincidence that criticisms and counter-criticisms as outlined above are centred on data-related and methodological issues. Yet it is not possible to eschew such limitations completely, and this study does not have a claim to be an exception in this regard. Instead, this paper is motivated by an intuition that possible explanations for the income-SWB link may not be exhausted. Therefore, the intended contribution to this debate will be offering a different perspective which derives insights from both sides, but also modifies several of their basic premises. The following discussion develops the main argument with regard to the two sides of the overall debate to find such a perspective. 


\section{Theory}

The argument proposed here is that, in addition to the effect of relative income, the real value of average income has both a direct/contextual effect and a mediated effect through relative income. The first aspect of the argument is simply an extension of recognizing that real income may have an effect. For the second aspect, based on studies which find that countries with high levels of SWB are also those with less unequal SWB (Fahey and Smyth, 2004), and that economic growth reduces the inequality in SWB (Clark et al., 2016; Veenhoven, 2005), one can expect narrowing ranges of SWB as income levels increase. Thus, this paper takes these findings one step further, as a sign that the relationship between relative income and SWB could become weaker as average income and SWB simultaneously increase. When the two aspects of the argument are considered together, the average income is taken both as a benchmark, above and below which relative positions are distributed, and as a determinant of how far such relative positions are distanced from the benchmark.

This argument implies partial agreement and disagreement with both sides of the debate as outlined above. First, it concurs with the Easterlin hypothesis in that it distinguishes relative income from real income and expects an autonomous influence of the former on SWB. Second, it concurs with the critics of the Easterlin hypothesis, because it does not dismiss the underlying relevance of real income, at least at the aggregate level or as a benchmark according to which relative positions are distributed. In other words, as a compromise, it is argued that a universal log-linear relationship between income and SWB exists at the background, which means that real/average income is positively associated with SWB while its returns are diminishing, but the relationship between relative income and SWB deviates from this relationship to a certain extent for specific distributions. Thereby, the range of SWB corresponding to each income distribution should be larger than what a single log-linear relationship would predict, but should get higher and narrower with rising average income than a relative-income-only model would predict.

This prediction aligns well with some of the earlier approaches to SWB-income relationship, in particular Schyn's (2002) study which finds empirical evidence for a similar argument. However, this study does not attempt at showing how this approach relates to Easterlin paradox and its critiques, or broader theoretical debates. In order to advance this approach in a more theoretically oriented direction and with due regard to Easterlin paradox, the argument proposed here will be built on the model proposed by Clark et al. (2008), as it embodies the idea that rising average income brings relatively small increases in SWB and flattening curves for relative income. More specifically, they formulate their model through the following functional form (p. 100):

$$
U=\beta_{1} \frac{y}{y+A}+\beta_{2} \ln \left(\frac{y}{\bar{y}}\right)
$$

where $y$ denotes real income, $\bar{y}$ national average, and $A$ a positive constant. However, several substantive modifications are necessary to adapt this equation to the argument proposed here, for two main reasons: first, there is little room for the direct effect of real income (except for small values of $y$ with respect to $A$ ), and second, the relationship between relative income and SWB flattens at a slow pace. In the authors' own words, respectively, first, "[t]he functional form here is deliberately chosen to ensure that the benefit of an across-the-board proportional rise in income 
tends to zero as income goes to infinity" (p. 100), and second, "the marginal utility of extra status never approaches zero, because in general [reference group income] rises in line with own income" (p. 101).

In order to strike the compromise as suggested, both of these tendencies should be reversed. For a direct effect of real income which is not bounded by a finite value and which always has positive albeit diminishing returns, $\beta_{1} \ln (\bar{y})$ will replace the first term of the equation. For the relationship between relative income and SWB to flatten more quickly, a function that is decreasing as income increases will be integrated to its coefficient. Since the slope of $\beta_{1} \ln (\bar{y})$, namely $\beta_{1} / \bar{y}$, converges to zero, it provides the perfect expression to account for the mediated effect of average income levels. Combining this variable slope with a fixed one for an autonomous effect on SWB, relative income will have the coefficient $\beta_{2}+\beta_{1} / \bar{y}$. Finally, another property of the logarithmic function will be used for rather stylistic purposes. Instead of $\ln (y / \bar{y})$, relative income will be expressed as $\ln (y)-\ln (\bar{y})$ which highlights more starkly two distinguishing features of this study. First, the effect of relative income is taken as the distribution of individuals around a benchmark set by the average income level which is represented here by $\ln (\bar{y})$ as all income measurements are on a logarithmic scale. Second, it is more appropriate to understand relativity in terms of distance from the reference value, rather than a ratio of it, since dividing by $\bar{y}$ or multiplying by $1 / \bar{y}$ outside the logarithm represents the mediated effect of average income on relative income.

Bringing together these modifications, the overall functional form of the argument will be given as:

$$
u(y \mid \bar{y})=\alpha+\beta_{1} \ln (\bar{y})+\left(\beta_{2}+\frac{\beta_{1}}{\bar{y}}\right)(\ln (y)-\ln (\bar{y}))
$$

where $\alpha$ is a constant, the first non-constant term integrates the direct effect of national average, and the second term represents relative income with a coefficient which is partially fixed and partially dependent on the slope of the first term. Thus, this formulation makes it possible to distinguish between three roles that average income plays according to the proposed argument: a direct contextual effect, the reference point for relative income, and a mediating effect on the relationship between relative income and SWB.

Following Clark et al. (2008) once again, a stylized visualization of this equation is provided by Figure 1, where the black lines represent the effect of relative income in three separate distributions, which are simulated using the above equation and arbitrary coefficients. As different from their visualization, however, these lines are presented against the background of an overall log-linear pattern, in order to illustrate the proposed compromise between the Easterlin hypothesis and its critiques. First, the relative income curves generally follow the universal log-linear pattern, in terms of both their vertical location and their diminishing slopes. Second, however, these relative income curves are not mere reflections of such a universal income-SWB relationship, but they deviate from it due to their autonomous relationship with SWB, or in other words, the fixed component of their coefficients.

Conceding the second point to the Easterlin hypothesis and the first point to its critics, these theoretical propositions can be reformulated into three components as empirically testable hypotheses. One should be able to observe three patterns: 
Figure 1: Approximation of absolute and relative income curves

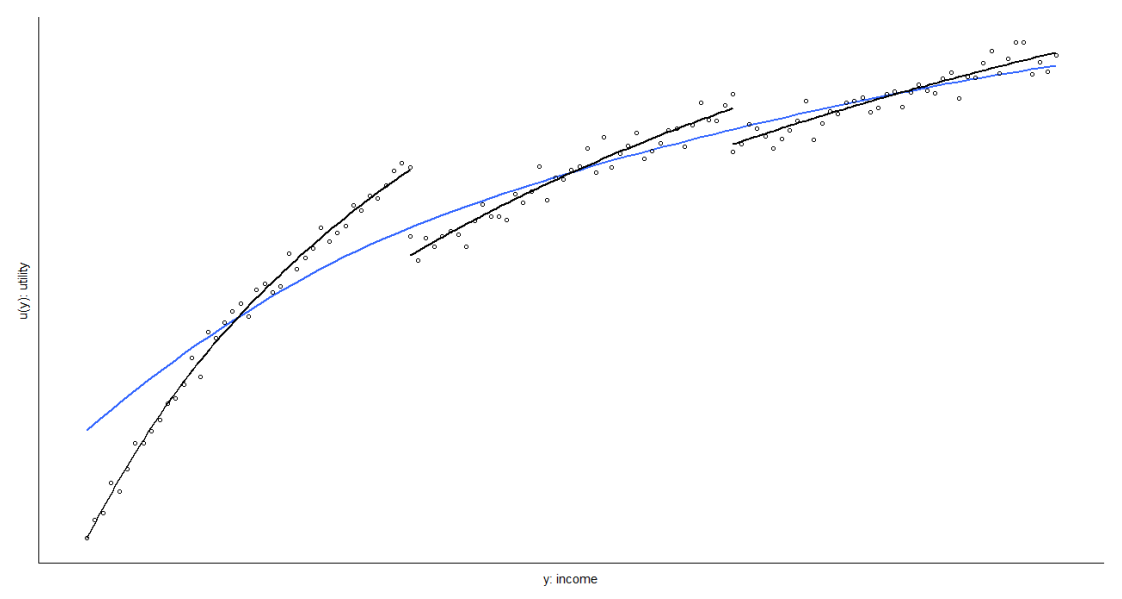

H1: the association between average income and SWB is positive (the direct/contextual effect of real/average income): $\beta_{1}>0$

H2: the association between relative income and SWB is larger than the one between average income and SWB (the autonomous effect of relative income): $\beta_{2}>\beta_{1}>0$

H3: the association between relative income and SWB gets weaker as the overall average income level increases (the mediated effect of average income): diminishing $\beta_{1} / \bar{y}$, as a corollary of a constant $\beta_{1}>0$

In order to test these hypotheses, the next section will translate the theoretical discussions of this section into an empirical strategy, and suggest definite measures of testing.

\section{Empirical strategy}

There are some strategic choices to be made before building a statistical model for empirical testing. The first one is concerned with longitudinal and cross-sectional options. As discussed above, these do not constitute perfect substitutes for each other, and longitudinal analyses tend to confirm the Easterlin hypothesis while cross-sectional analyses tend to find the opposite. The main problem with the former is limited availability of data covering sufficiently long periods of time. In particular, the even more restricted availability of individual-level panel data eliminates the possibility of testing in the same model variables measured at individual and country-levels. In this respect, it is difficult to claim the generalizability of findings beyond a group of countries that can be represented by those where suitable data are available. For this reason, the following discussions will adopt a cross-sectional logic, while it is acknowledged that this may not yield the same results for separate time series. In other words, this caveat should be noted: 'higher income across countries' will not necessarily mean 'rising income in a country'.

The second choice is concerned with fixed-effect or mixed-effect (also known as multilevel, hierarchical) regression models. Since cross-national datasets are built on country-based samples, the problem of non-independence of observations should be addressed in one of these ways. Fixed- 
effect models are used extensively to study SWB (e.g. Alesina et al., 2004; Helliwell and Huang, 2014), but there are several drawbacks associated with them. For instance, country-level indicators, such as average income, are likely to be confounded with the fixed country effects, as documented by Verme (2011) with regard to multicollinearity and high sensitivity of results to the fixed effects. In this respect, mixed-effect models provide a more suitable alternative: their application in SWB studies has become increasingly popular (e.g. Ahn et al., 2015; Delhey and Dragolov, 2014), and proven useful in addressing similar questions (Schyns, 2002). Furthermore, one of the main objectives of the empirical strategy is modelling variable slopes for each country, for which mixedeffect models are better equipped. This focus also constitutes the main contribution of this paper to previous analyses based on multilevel models.

In this respect, the proposed associations will be tested against a null hypothesis that SWB is only shaped by relative income and several other individual factors which have been identified by previous works in the field. Recognizing that part of the random variation can also come from the country-level, the baseline will be set by the following equation estimating well-being $(U)$ with a random-intercept model:

$$
U_{i c}=\alpha+\beta r_{i c}+\sum_{n} \zeta_{n} X_{n, i c}+v_{c}+\varepsilon_{i c}
$$

where subscripts denote individual $i$ from country $c$, the variable $r$ is relative income, $X$ represents $n$ control variables, $v$ is country-level error term resulting in varying intercepts and $\varepsilon$ is the individual-level error term. On this basis, the first step will be testing the significance of the country-level indicator of interest given by $y$ for average income:

$$
U_{i c}=\alpha+\beta r_{i c}+\gamma \ln \left(y_{c}\right)+\sum_{n} \zeta_{n} X_{n, i c}+v_{c}+\varepsilon_{i c}
$$

While this model provides a preliminary test for the direct effect of average income, considering this alongside the mediated effect will require variable coefficients of relative income across countries, hence rewriting $\beta$ as $\beta_{c}=\hat{\beta}+\hat{v}_{c}$, where $\hat{v}_{c}$ introduces the random slopes to the model. Additionally, the effect of relative income is conceptualized as depending on average income as well, which expands the equation to $\beta_{c}=\hat{\beta}+\theta \ln \left(y_{c}\right)+\hat{v}_{c}$. Incorporating this with the equation (2) will result in an interaction term in the fully specified model:

$$
U_{i c}=\alpha+\hat{\beta} r_{i c}+\gamma \ln \left(y_{c}\right)+\sum_{n} \zeta_{n} X_{n, i c}+\theta \ln \left(y_{c}\right) r_{i c}+\hat{v}_{c} r_{i c}+v_{c}+\varepsilon_{i c}
$$

In this sense, the main argument and the three hypotheses comprising it will be tested with respect to the following estimates: $\gamma$ should be positive and significant to show the direct effect of average income (H1); $\hat{\beta}$ should be larger than $\gamma$ to show that relative income has an autonomous influence, hence departs from the values predicted by average income to a meaningful extent $(\mathrm{H} 2)$; and $\theta$ should be negative to show that the overall effect of relative income decreases with higher values of average income (H3).

\section{Data and variables}

The sixth wave (2010-2014) of World Values Survey (WVS, 2016) will be used to test the model proposed above. In addition to general requirements of data quality, this dataset satisfies two 
particularly important conditions: a reasonable degree of variation in average income, and a sufficiently large number of countries. For the first condition, although Deaton (2008) does not find the earlier waves of WVS fully adequate due to the underrepresentation of lower income countries, the sixth wave corrects this shortcoming to a certain extent. In this sense, this study also aims to offer an update on earlier similar works (e.g. Schyns, 2002), in order to have a better idea as to whether the problems related to data quality had also affected their findings. In addition, WVS is more accessible than alternative options, such as Gallup World Poll, and thus more widely used in SWB studies. The main motivation of this paper is to offer an additional perspective to the existing debates, rather than challenging one position or the other on the ground of the data-sensitivity of results. Therefore, while the accuracy of this perspective can be tested and retested with different datasets, the reasonable choice is starting with the more accessible and widely used option.

For the second condition, one of the often ignored methodological requirements of multilevel modelling is that the number of higher-level units should conform to general sample size standards (Snijders and Bosker, 1999, p. 140). According to more definite estimates of this sample size for cross-national datasets, the absolute minimum for a simple multilevel model should be around 25 countries, and higher for more complex models (Bryan and Jenkins, 2016). Since the proposed model includes a country-level variable, random slopes and a cross-level interaction term, the target should be somewhat above 25. The sixth wave of WVS contains representative samples from 60 countries (although two will be dropped due to missing variables), which can be taken as satisfactory with regard to the degree of complexity of the tested model.

Previous studies increased the number of country-level observations in several ways, which also compromises the quality of the sample of countries, notably its representativeness. One option is appending European Values Survey data into WVS (e.g. Kelley and Evans, 2017; Rözer and Kraaykamp, 2012), which biases the sample towards Europe and high-income countries. Another option is focusing only on WVS but using all waves (e.g. Bjørnskov et al., 2010), hence obtaining a high number of country-year units, which biases the sample towards the countries which have taken part in previous waves more frequently. The added value of this strategy is also dubious due to low variability for each country across time or similarity of time trends across countries (Verme, 2011, p. 126). Finally, a usually underplayed issue with the earlier waves of WVS, to which Stevenson and Wolfers (2008) draws attention, is that not all national samples were representative, since mostly urban and more affluent citizens of lower income countries were interviewed during these surveys (pp. 13-14).

As for the particularities of variables, first, life satisfaction will be preferred as a measure of SWB over happiness, or over an index combining the two, while both options are available in WVS data. This strong preference is due to its likelihood of being derived from more stable and less momentary self-evaluations about one's well-being. For example, it is found more strongly associated with material indicators of well-being (Diener et al., 2010), with indicators derived from the capabilities approach as opposed to a strictly hedonistic understanding (Anand et al., 2011), and with income (Kahneman and Deaton, 2010; Krueger and Schkade, 2008). Although it is not a perfect substitute for experienced utility, it provides a better approximation for these reasons. It is measured on a scale of $1-10$, higher values meaning more satisfaction, which provides a large enough range to treat the measurement as numeric rather than ordered. Following van 
Praag and Ferrer-i-Carbonell (2008), it is assumed that respondents make the necessary cardinal judgements when answering the question, and the numerical value of their expressed satisfaction is meaningful enough that further cardinalization is not essential. Thus the models will be built on linear regression.

The income of respondents is also reported on a scale of 1-10, constructed with nationally defined brackets in such a way that national distributions resemble normal distribution. This measurement will be taken to represent relative income for two reasons. First, although relativity can be understood in terms of comparison with a reference point which is not necessarily the same for everyone living in a country, the argument advanced in this paper is concerned with relativity in terms of the national average, and the value assigned to each unit of observation is comparable only within its country. In this sense, the adjustment of brackets corresponding to each value of the 1-10 scale with respect to national parameters, namely the central tendency, dispersion and skewedness of the income distribution, assigns each unit of observation to a position relative to the average income.

Second, the approximation of normal distribution is possible by defining larger brackets for higher values of the 1-10 scale, since one can reasonably expect that income distributions are positively skewed. Therefore, this measurement strategy has a similar effect as using a logarithmic transformation on income, concurring with the functional form used in the Theory section. The real levels of individual income could also have been included by simulating these through known national parameters, but the functional form of the argument and the empirical strategy were designed in a way that makes this unnecessary. In other words, the average income positions countries with respect to globally comparable real income levels, and the relative position of each unit with respect to its country's average also indicates the global position of that unit, when both are taken into account. The measurement of average income will follow the standard practice in using the purchasing power parity-based GDP per capita, as reported by the World Bank.

Finally, regarding control variables, the aim is to build a model as extensive as possible, since ecological correlation may influence the relative strength of individual and national incomes (Ma and Zhang, 2014). The studies of SWB are not limited to its relationship with income, and many other individual and social factors are found to be associated with well-being. These include health, employment status, personal autonomy, social trust/capital, trust in institutions, demographics, etc. (e.g Dolan et al., 2008; Helliwell, 2003; Helliwell and Putnam, 2004; Inglehart et al., 2008; Layard, 2005), which can be found in the survey data with individual-level measurement. On one hand, it should be noted that an important group of these factors are conceptualized and operationalized as attitudinal variables. Given the subjective nature of the dependent variable as well, their correlation could be due to common mood or personality effects. Nonetheless, they are included in the model not as the main analytical focus, but on the contrary, with an intention to make the model more conservative by controlling for as much subjective attributes as possible, while the main focus remains on the non-attitudinal income variables.

On the other hand, some of these factors may account for certain functions attributed to income. In this sense, their inclusion in the model as control variables will serve the purpose of accounting for other indirect effects of income on SWB. For example, in addition to the variables adopted from previous studies, subjective perception of social class is included to control for one's position 
in society, so that income ranks more clearly represent the comparisons made in monetary terms rather than social status; and similarly education level is included to control for possible ways in which agents can translate income into social status. No country-level controls are used, mostly because the low number of countries would damage the reliability of estimates with additional variables. Instead, the relevance of unobserved country characteristics can be informally deduced from the extent of random effects, and these will constitute the main focus of the Discussion section.

\section{Analysis}

The main argument will be evaluated by testing how well the specified model fits with the data from the WVS sixth wave. The results of the multilevel linear models are summarized in Table 1. The table initially presents an empty 'variance component model' in the first column to differentiate the random variation in individual and country levels. The equation (3) follows in the second column with only individual level fixed effects, and the equation (4) in the third column introduces the country-level fixed effect of GDP per capita. The only difference in the fourth column is random slopes for relative income. The fifth column presents the full model as specified by equation (5), with the addition of the cross-level interaction term. The model goodness of fit is assessed by comparing the difference in deviance statistics between each model and the previous one. Since all comparisons return statistically significant $\chi^{2}$, the full model can be endorsed as providing an important improvement in explanatory power as compared to smaller models.

To begin with the variance component model, approximately $11 \%$ of the total random effects is due to the country-level variance, which indicates the adequacy of using mixed-effect models. Next, the introduction of individual-level variables in Model 2-relative income and a list of controls-reduces country-level as well as individual-level random effects. Thereby, the variation of SWB across countries is partly due to the differences represented by the control variables. Continuing the examination of random effects with income-related variation, first, the introduction of GDP per capita in Model 3 results in a further decrease in the country-level variance. Second, allowing random slopes for relative income in Model 4 brings a slight decrease in the variance of intercepts, but the total country-level random effects are approximately at the same level as Model 2: 0.060 and 0.061 respectively. In other words, the increase in the random effects due to varying slopes is more or less equivalent to the decrease which was brought by the introduction of GDP per capita as a fixed effect. Finally, the fact that cross-level interaction term reduces this level back to 0.056 testifies to the visible, albeit small, association between random slopes and national average income levels.

As for the fixed effects, the results for individual-level variables largely conform to the findings of existing studies: with the exception of education, variables representing health, employment, social class, personal autonomy, social trust, trust in political institutions, and demographics are all significant determinants of SWB, and the coefficients retain their significance in further model specifications. Regarding the main independent variable of interest, relative income displays a strong relationship with SWB as one standard deviation change in income rank is associated with 
Economics: The Open-Access, Open-Assessment E-Journal 12 (2018-43)

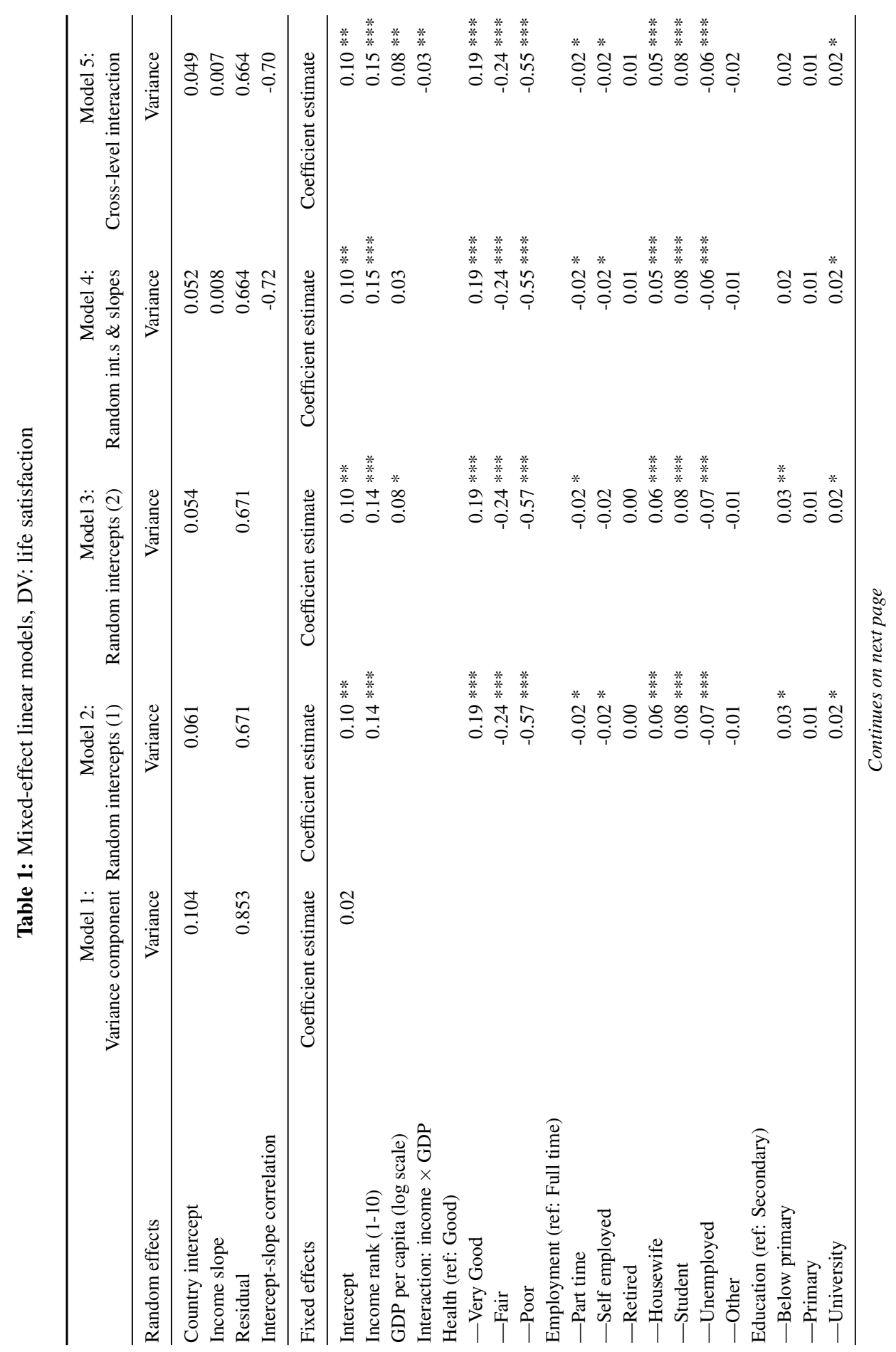




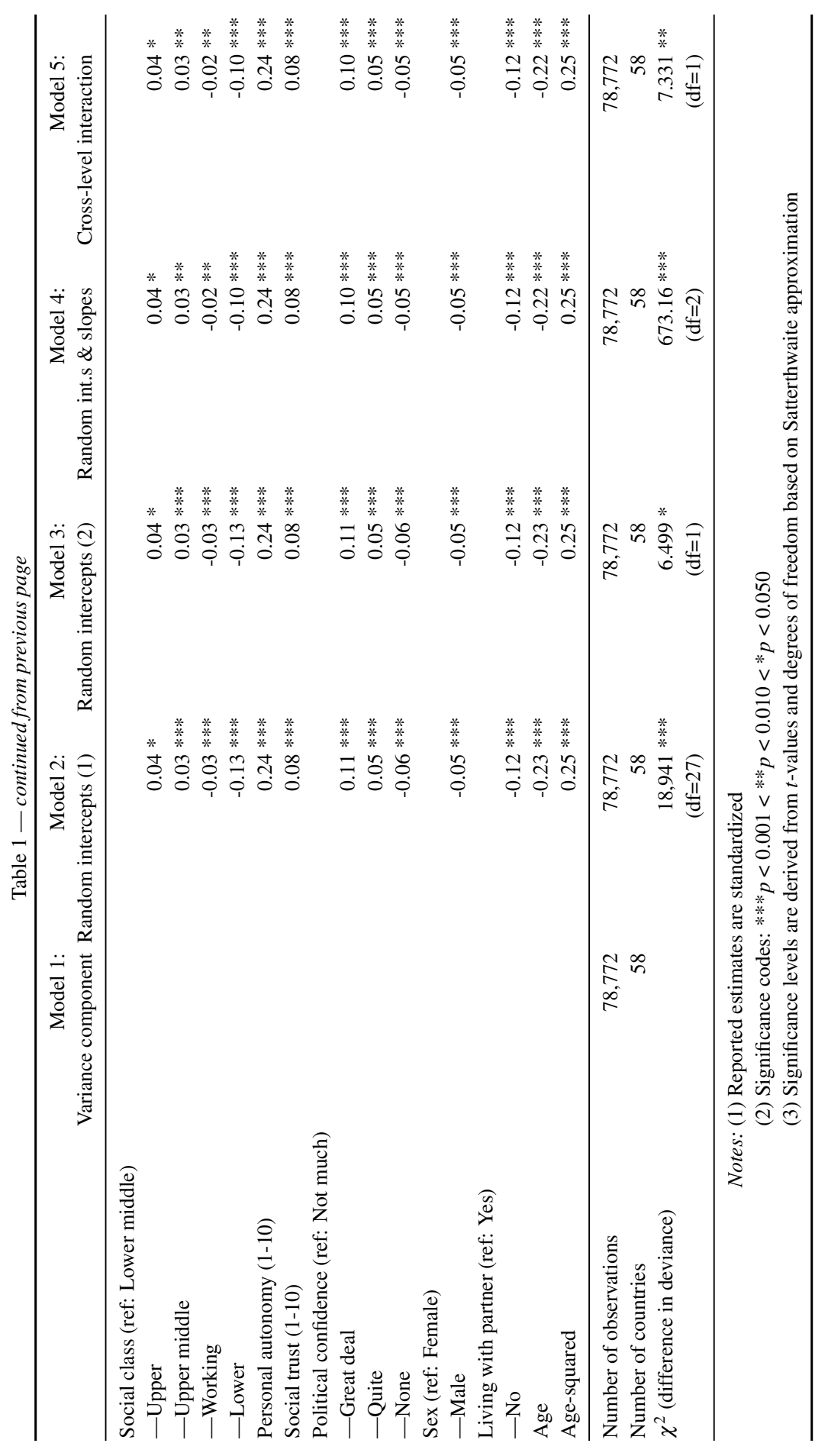


approximately 0.15 standard deviation change in life satisfaction. However, when compared with other individual-level variables, income is not necessarily the only important one.

For example, to compare it with the variables which are also measured at a numeric scale, although the coefficient of income is larger than that of social trust (0.08), it is considerably smaller than that of personal autonomy (0.24). Among categorical variables, subjective health displays a straightforward pattern; the worse one's health gets, the larger are the SWB losses $(0.19,0.24$ and 0.33 from very good to poor). Each change in the ladder is larger than what is accounted for by one standard deviation of relative income. For employment, not seeking work (housewives and students) has a positive impact and being unable to find work (unemployed) has a negative impact of similar magnitudes as compared to being in full employment, and this level is half as much as what one standard deviation of relative income brings. The change associated with each category of social class is even smaller, except for the lowest class whose difference from lower middle is comparable to one standard deviation of relative income. The effect of the confidence in political institutions is quite monotone with approximately 0.06 standard deviation for each category. Regarding demographics, the difference between biological sexes is 0.05 , while living with a partner has an effect comparable with one standard deviation of relative income. Finally, the negative coefficient of age and the positive coefficient of age-squared with almost equal magnitudes reaffirms its U-shaped relationship with life satisfaction.

The triangular relationship among life satisfaction, income rank and GDP per capita implies interesting patterns. First, when GDP per capita is added alone, it yields a significant coefficient; although this finding is not compatible with a strict interpretation of the Easterlin paradox, it is expected and unsurprising in cross-sectional analysis. Yet it should be remarked that the coefficient of GDP per capita is considerably smaller than that of income rank ( 0.08 and 0.14 respectively), suggesting that within-country income differentials are more important than cross-national ones. These findings concur with the posited properties of $\gamma$ and $\hat{\beta}$ as discussed in the Empirical strategy section, thus confirm the Hypotheses 1 and 2 as formulated in the Theory section.

Second, when the slopes of income rank are allowed vary, the impact of GDP per capita is reduced to insignificant levels (0.03): while this compromises the confirmation of Hypothesis 1, it can also be interpreted as the random effect of varying slopes and the fixed effect of average income corresponding more or less to the same cross-country variation. Furthermore, the large and negative correlation between random slopes and intercepts shows that country-specific relative income regression lines are flatter when they are positioned at vertically higher levels. Given the positive coefficient of GDP per capita from Model 3, this correlation would also be reflected in the relationship between GDP and varying slopes; the cross-level interaction term is intended to test if this is true.

The significant and negative coefficient of the interaction term confirms that relative income curves get slightly flatter at higher levels of average income. In other words, the coefficient estimate concurs with the expected property of $\theta$ as discussed in the Empirical strategy section, thus confirms the Hypothesis 3 as formulated in the Theory section. It should also be remarked that the main term for GDP per capita reverts back to its original level: once the mediated effect of average income is accounted for, a significant direct effect can still be observed, and Hypothesis 1 can be retained. Therefore, overall, the data confirm all posited associations between income 
and SWB: relative income has an autonomous direct (fixed) effect, and average income is still relevant partly because it also has a direct effect, and partly because it shapes the country-specific relationships between relative income and SWB.

\section{Discussion}

While the full model displays the expected properties and provides a higher explanatory power than the less extensive options, a closer look is necessary to ascertain how well the model fits with the data. At the individual level, standard diagnostic tests, such as those concerned with influential observations, multicollinearity and the distribution of residuals, do not return problematic results. Furthermore, different combinations of control variables do not alter the findings on relative income and GDP per capita. On these bases, the analysis relies on a robust model.

Nevertheless, it is still necessary to examine the model fit with regard to the country-level, which will also shed further light on one of the central emphases of this paper, namely, how the relationship between SWB and individual income ranks varies with respect to GDP per capita. As seen in the below scatter-plots (Figures 2 and 3), the model displays heteroskedastic features, since middle income countries deviate more from the regression line as compared to lower and higher income countries. The main implication of such a distribution is that more country-level variables are needed for a better model specification, whereas this is not attempted in the present study due to the low number of countries. Apart from larger residuals among middle income countries, there do not seem to exist cases which disproportionately influence the slope of the curve, hence coefficient estimates. Thereby, retaining the confidence in the conclusions reached on coefficient estimates, the discussion below will focus on the implications of these peculiar scatter-plots for different countries and country groups.

The main argument of this paper has suggested two patterns for the country-level variation, which broadly correspond to random intercepts and slopes. First, it is argued that average income could have a direct effect on SWB, thus it would partially determine the vertical differences among relative income curves. This corresponds to the addition of GDP per capita as a fixed effect by Model 3 to explain some part of the random intercepts of Model 2. This reasoning is valid insofar as the intercepts are positively correlated to the respective values of GDP per capita, since a positive effect of the latter on SWB is expected. While this is confirmed by the significant coefficient of GDP per capita in Model 3, Figure 2 enables the examination of the distribution of countries in further detail.

The linear fit as presented in this figure yields a standardized coefficient of 0.33 (not reported in the figure); one standard deviation change in GDP per capita accounts for one-third standard deviation change in the intercepts. However, there are several cases which clearly display large residuals. Above the regression line, four Latin American countries have unusually large intercepts: Mexico, Colombia, Brazil, Ecuador. This observation confirms several studies which have already found that the SWB levels reported in Latin American countries tend to be higher than what is predicted by global models. Meanwhile, Peru and Chile are closer to the predicted values, and they do not necessarily follow the same pattern. Below the regression line, five Middle-Eastern countries have relatively large negative residuals: Egypt, Palestine, Tunisia, Iraq and Kuwait. However, 
Figure 2: Random intercepts and GDP per capita

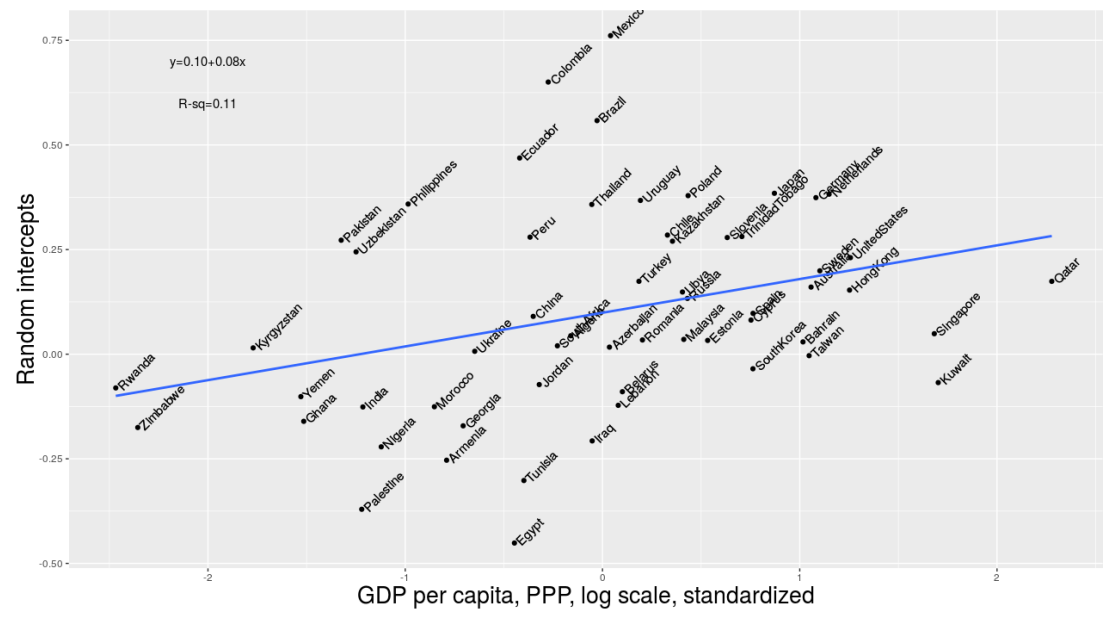

given smaller residuals of other countries which are similar to them in terms of geographic, social and economic characteristics, a regional or cultural pattern cannot be readily inferred. Yet ongoing civil conflicts and political instability are among possible explanations for unusually lower levels of SWB. Overall, average income explains only part of the international differences in SWB, and the remaining variation is likely to result from unobserved national or regional characteristics.

Second, it is argued that average income could have a mediated effect on SWB, thus it would partially determine the slope of relative income curves. This corresponds to the addition of the cross-level interaction term by Model 5 to explain part of the random intercepts of Model 4. This reasoning is valid insofar as the slopes are negatively correlated to the respective values of GDP per capita, since the latter is conceptualized in terms of diminishing returns. While this is confirmed by the significant coefficient of the interaction term in Model 5, Figure 3 can be used for further examination of how countries are distributed.

Figure 3: Random slopes and GDP per capita

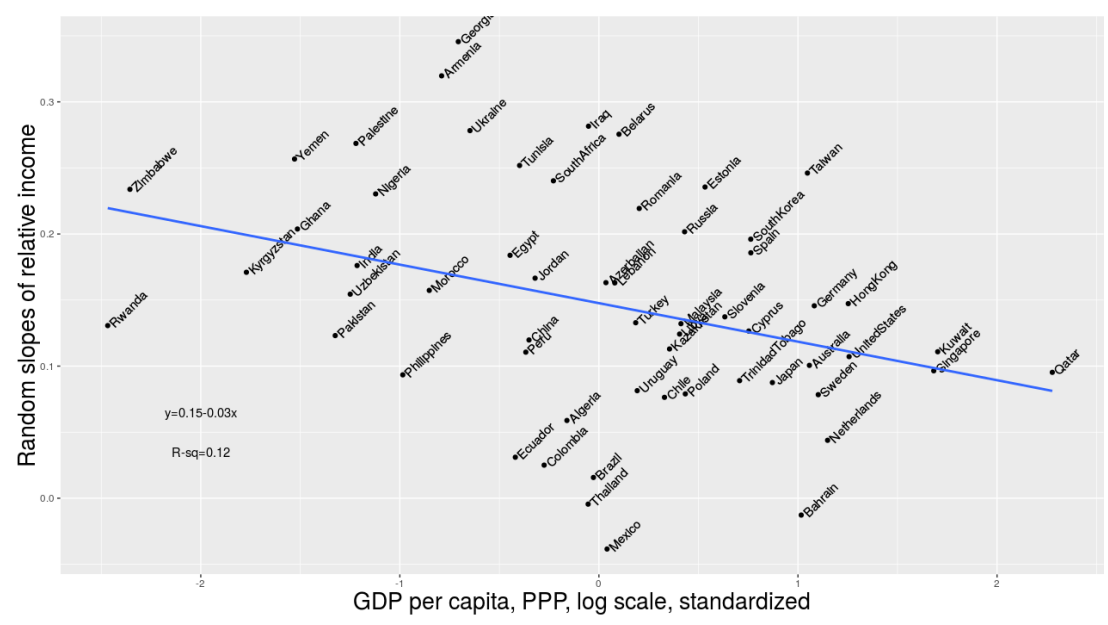


The standardized coefficient of this linear fit is -0.34 (not reported in the figure); similarly to above, one standard deviation change in GDP per capita accounts for approximately one-third standard deviation change in the slopes in the opposite direction. Again similarly, there are country groups which display large residuals. The same four Latin American countries are grouped together in this plot as well, sharing the common feature of having flat relative income curves. When this is considered together with their distinctively high intercepts, they constitute the cases which embody the relationship between high levels of SWB and low inequality in SWB without necessarily having high levels of average income. On the other side, four ex-Soviet countries can be taken as a group of unusually steep relative income curves: Georgia, Armenia, Ukraine and Belarus. Since there are other ex-Soviet countries in the sample with a closer conformity to the general pattern, it is difficult to decide the extent to which the shared historical context is responsible for this similarity. Yet it should be reiterated that unobserved national or regional characteristics can be taken as the reason for this degree of dispersion.

Finally, considering random slopes and intercepts together, Figure 4 displays a plot comparable to Figure 1 which embodies an idealized form of the main argument. In this plot, countries are horizontally positioned according to their real GDP per capita values, and vertically positioned according to their predicted values of SWB based on random intercepts and GDP per capita (log-scale) multiplied by the coefficient from Model 5. The blue line represents the log-linear fit, and each black line segment takes random slopes from respective countries.

The comparison with the idealized form of the argument naturally reveals visible discrepancies, yet it illustrates the suggested compromise between the Easterlin hypothesis and its critics. First, the vertical differences among countries at similar levels of economic development are still quite large. This observation suggests that the logarithm of GDP per capita accounts for only a small portion of direct country effects, and the rest constitutes random intercepts. Thus it marks the first point of compromise for the main debate in the literature: the relationship between average income and average SWB is relatively weak, yet to a certain degree it exists. Second, in a considerable number of cases, the country-specific slopes do not reflect the slope of the log-linear curve. This

Figure 4: GDP per capita with Random intercepts and slopes

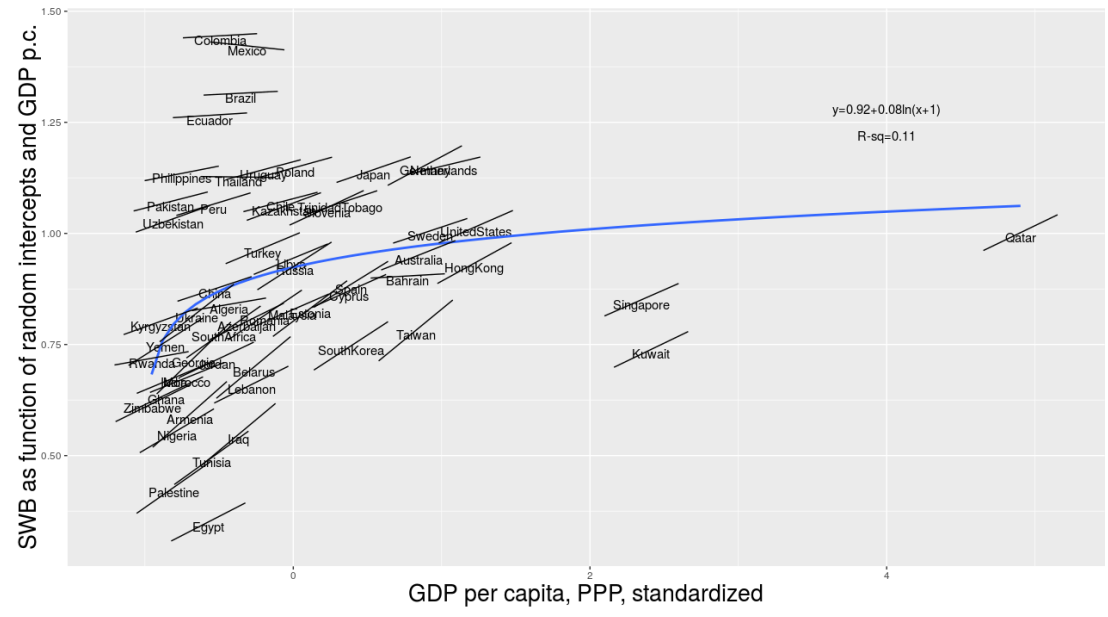


observation points to the limitation of taking the inverse relationship between GDP per capita and slopes of relative income as the mediated effect of the former. Thus it also marks the second point of compromise: relative income curves tend to flatten as GDP per capita increases, but it is also true that there is a fixed component in their slopes and that cross-national differences in these slopes are not fully accounted for by GDP per capita.

\section{Conclusion}

To summarize, this paper offered a compromise between two accounts, one which accepts the main premises of the Easterlin paradox and one which refuses them. It has argued that while there is a limited direct effect of average income, this also shapes the relationship between relative income and SWB, in addition to the fixed autonomous component of relative income. Analyzing the latest wave of WVS with a mixed-effect model, the results confirm this argument. However, further examinations of direct and mediated effects reveal that there is a considerable amount of crossnational variation that GDP per capita cannot explain. This is especially true for middle-income economies, but despite this variation, the link between the level of SWB and the slope of relative income curve seems to hold. Thus, one of the main implications of this finding is that providing overall higher SWB is usually analogous to closing the gap between low and high levels of SWB, and higher average income can partially serve this purpose.

Furthermore, when the countries which returned unusually high or low statistics are discussed, these can be reasonably linked to certain geographic, cultural and historical commonalities. Thereby, some national characteristics, including both economic and non-economic factors, may account for the remaining variation. Several implications for future research follow from this conclusion. For economic characteristics, a relevant country-level indicator is inequality, being a key feature of income distribution, and there is a long tradition on its relationship with SWB (e.g. Morawetz et al., 1977 as an early study), but the findings are even more inconclusive, varying between negative, insignificant and positive effects (see Schneider, 2016 for a recent review). The possibilities that its effect may have the form of an inverted U-shaped curve (Senik, 2004; Wang et al., 2014), and that it may be mediated by a variety of factors (Alesina et al., 2004; Senik, 2005), make income inequality a particularly challenging variable to include in standard models. But these also mean that conditional effects of inequality can make useful contributions to models such as the one analyzed in this paper.

As for non-economic variables, political factors can potentially contribute to the explanation of SWB. For example, at the individual level, personal autonomy proves to be one of the strongest predictors of SWB, which could also be reflected at the country-level indicators. Earlier studies, such as those conducted by Helliwell and Huang (2008), Inglehart et al. (2008) and Radcliff (2001) indeed confirm the relevance of democracy, good governance and social tolerance for SWB, and the list can be extended to many other political factors. However, due to the limited number of countries in the world, general limitations of data availability, and the problematic nature of comparing political factors across polities, it does not seem plausible to test such extensive models in the near future. For this reason, subnational political and/or territorial units should be considered 
for future research on distinguishing between individual- and aggregate-level determinants of SWB.

\section{References}

Ahn, H., Roll, S. J., Zeng, W., Frey, J. J., Reiman, S., and Ko, J. (2015). Impact of Income Inequality on Workers' Life Satisfaction in the U.S.: A Multilevel Analysis. Social Indicators Research, 128(3): 1347-1363. URL http://dx.doi.org/10.1007/s11205-015-1082-7.

Alesina, A., Di Tella, R., and MacCulloch, R. (2004). Inequality and Happiness: Are Europeans and Americans Different? Journal of Public Economics, 88(9-10): 2009-2042. URL http: //dx.doi.org/10.1016/j.jpubeco.2003.07.006.

Anand, P., Krishnakumar, J., and Tran, N. B. (2011). Measuring Welfare: Latent Variable Models for Happiness and Capabilities in the Presence of Unobservable Heterogeneity. Journal of Public Economics, 95(3-4): 205-215. URL http://dx.doi.org/10.1016/j.jpubeco.2010.11.007.

Bjørnskov, C., Dreher, A., and Fischer, J. A. (2010). Formal Institutions and Subjective Well-being: Revisiting the Cross-country Evidence. European Journal of Political Economy, 26(4): 419-430. URL http://dx.doi.org/10.1016/j.ejpoleco.2010.03.001.

Bryan, M. L., and Jenkins, S. P. (2016). Multilevel Modelling of Country Effects: A Cautionary Tale. European Sociological Review, 32(1): 3-22. URL http://dx.doi.org/10.1093/esr/jcv059.

Clark, A. E., Flèche, S., and Senik, C. (2016). Economic Growth Evens Out Happiness: Evidence from Six Surveys. Review of Income and Wealth, 62(3): 405-419. URL http://dx.doi.org/10. 1111/roiw.12190.

Clark, A. E., Frijters, P., and Shields, M. A. (2008). Relative Income, Happiness, and Utility: An Explanation for the Easterlin Paradox and Other Puzzles. Journal of Economic Literature, 46(1): 95-144. URL http://dx.doi.org/10.1257/jel.46.1.95.

Deaton, A. (2008). Income, Health, and Well-Being around the World: Evidence from the Gallup World Poll. The Journal of Economic Perspectives, 22(2): 53-72. URL http://dx.doi.org/10. $1257 / 089533008785492315$.

Delhey, J., and Dragolov, G. (2014). Why Inequality Makes Europeans Less Happy: The Role of Distrust, Status Anxiety, and Perceived Conflict. European Sociological Review, 30(2): 151-165. URL http://dx.doi.org/10.1093/esr/jct033.

Di Tella, R., and MacCulloch, R. J. (2010). Happiness Adaptation to Income Beyond "Basic Needs". In E. Diener, D. Kahneman, and J. Helliwell (Eds.), International Differences in Well-Being, pages 217-246. Oxford ; New York: Oxford University Press.

Diener, E., Kahneman, D., Tov, W., and Arora, R. (2010). Income's Association with Judgments of Life Versus Feelings. In E. Diener, D. Kahneman, and J. Helliwell (Eds.), International Differences in Well-Being, pages 3-15. Oxford ; New York: Oxford University Press. 
Dolan, P., Peasgood, T., and White, M. (2008). Do we really know what makes us happy? A review of the economic literature on the factors associated with subjective well-being. Journal of Economic Psychology, 29(1): 94-122. URL http://dx.doi.org/10.1016/j.joep.2007.09.001.

Easterlin, R. A. (1974). Does Economic Growth Improve the Human Lot? Some Empirical Evidence. In P. A. David, and M. W. Reder (Eds.), Nations and Households in Economic Growth: Essays in Honor of Moses Abramovitz, pages 89-125. New York: Academic Press.

Easterlin, R. A. (1995). Will Raising the Incomes of All Increase the Happiness of All? Journal of Economic Behavior \& Organization, 27(1): 35-47. URL http://dx.doi.org/10.1016/ 0167-2681(95)00003-B.

Easterlin, R. A. (2001). Income and Happiness: Towards a Unified Theory. The Economic Journal, 111(473): 465-484.

Easterlin, R. A. (2005a). Diminishing Marginal Utility of Income? Caveat Emptor. Social Indicators Research, 70(3): 243-255. URL http://dx.doi.org/10.1007/s11205-004-8393-4.

Easterlin, R. A. (2005b). Feeding the Illusion of Growth and Happiness: A Reply to Hagerty and Veenhoven. Social Indicators Research, 74(3): 429-443. URL http://dx.doi.org/10.1007/ s11205-004-6170-z.

Easterlin, R. A. (2017). Paradox Lost? Review of Behavioral Economics, 4(4): 311-339. URL http://dx.doi.org/10.1561/105.00000068.

Easterlin, R. A., and Sawangfa, O. (2010). Happiness and Economic Growth: Does the Cross Section Predict Time Trends? Evidence from Developing Countries. In E. Diener, D. Kahneman, and J. Helliwell (Eds.), International Differences in Well-Being, pages 166-216. Oxford ; New York: Oxford University Press.

Fahey, T., and Smyth, E. (2004). Do Subjective Indicators Measure Welfare? Evidence from 33 European Societies. European Societies, 6(1): 5-27. URL http://dx.doi.org/10.1080/ 1461669032000176297.

Graham, C. (2011). Does More Money Make You Happier? Why so much Debate? Applied Research in Quality of Life, 6(3): 219. URL http://dx.doi.org/10.1007/s11482-011-9152-8.

Hagerty, M. R., and Veenhoven, R. (2003). Wealth and Happiness Revisited: Growing National Income Does Go with Greater Happiness. Social Indicators Research, 64(1): 1-27. URL http://dx.doi.org/10.1023/A:1024790530822.

Helliwell, J. F. (2003). How's Life? Combining Individual and National Variables to Explain Subjective Well-being. Economic Modelling, 20(2): 331-360. URL http://dx.doi.org/10.1016/ S0264-9993(02)00057-3.

Helliwell, J. F., and Huang, H. (2008). How's Your Government? International Evidence Linking Good Government and Well-Being. British Journal of Political Science, 38(4): 595-619. URL http://dx.doi.org/10.1017/S0007123408000306. 
Helliwell, J. F., and Huang, H. (2014). New Measures of the Costs of Unemployment: Evidence from the Subjective Well-Being of 3.3 Million Americans. Economic Inquiry, 52(4): 1485-1502. URL http://dx.doi.org/10.1111/ecin.12093.

Helliwell, J. F., and Putnam, R. D. (2004). The Social Context of Well-being. Philosophical Transactions of the Royal Society of London. Series B, Biological Sciences, 359(1449): 14351446. URL http://dx.doi.org/10.1098/rstb.2004.1522.

Inglehart, R., Foa, R., Peterson, C., and Welzel, C. (2008). Development, Freedom, and Rising Happiness: A Global Perspective (1981-2007). Perspectives on Psychological Science, 3(4): 264-285. URL http://dx.doi.org/10.1111/j.1745-6924.2008.00078.x.

Kahneman, D. (1994). New Challenges to the Rationality Assumption. Journal of institutional and theoretical economics, 150(1): 18-36.

Kahneman, D., and Deaton, A. (2010). High Income Improves Evaluation of Life but not Emotional Well-being. Proceedings of the National Academy of Sciences of the United States of America, 107(38): 16489-16493. URL http://dx.doi.org/10.1073/pnas.1011492107.

Kahneman, D., and Krueger, A. B. (2006). Developments in the Measurement of Subjective Well-Being. The Journal of Economic Perspectives, 20(1): 3-24. URL http://dx.doi.org/10.1257/ 089533006776526030 .

Kahneman, D., Krueger, A. B., Schkade, D., Schwarz, N., and Stone, A. (2004). Toward National Well-being Accounts. The American Economic Review, 94(2): 429-434. URL 10.1257/0002828041301713.

Kahneman, D., Krueger, A. B., Schkade, D., Schwarz, N., and Stone, A. A. (2006). Would You Be Happier If You Were Richer? A Focusing Illusion. Science, 312(5782): 1908-1910. URL http://dx.doi.org/10.1126/science.1129688.

Kahneman, D., and Thaler, R. H. (2006). Anomalies: Utility Maximization and Experienced Utility. The Journal of Economic Perspectives, 20(1): 221-234. URL http://dx.doi.org/10.1257/ 089533006776526076.

Kahneman, D., Wakker, P. P., and Sarin, R. (1997). Back to Bentham? Explorations of Experienced Utility. The Quarterly Journal of Economics, 112(2): 375-405. URL http://dx.doi.org/10.1162/ 003355397555235 .

Kelley, J., and Evans, M. D. R. (2017). Societal Inequality and Individual Subjective Well-being: Results from 68 Societies and over 200,000 Individuals, 1981-2008. Social Science Research, 62: 1-23. URL http://dx.doi.org/10.1016/j.ssresearch.2016.04.020.

Krueger, A. B., and Schkade, D. A. (2008). The Reliability of Subjective Well-being Measures. Journal of Public Economics, 92(8-9): 1833-1845. URL http://dx.doi.org/10.1016/j.jpubeco. 2007.12.015. 
Layard, P. R. G. (2005). Happiness: Lessons from a New Science. London: Penguin Press.

Ma, Y. Z., and Zhang, Y. (2014). Resolution of the Happiness-Income Paradox. Social Indicators Research, 119(2): 705-721. URL http://dx.doi.org/10.1007/s11205-013-0502-9.

Morawetz, D., Atia, E., Bin-Nun, G., Felous, L., Gariplerden, Y., Harris, E., Soustiel, S., Tombros, G., and Zarfaty, Y. (1977). Income Distribution and Self-Rated Happiness: Some Empirical Evidence. The Economic Journal, 87(347): 511-522. URL http://dx.doi.org/10.2307/2231556.

Proto, E., and Rustichini, A. (2013). A Reassessment of the Relationship between GDP and Life Satisfaction. PLOS ONE, 8(11): e79358. URL http://dx.doi.org/10.1371/journal.pone.0079358.

Radcliff, B. (2001). Politics, Markets, and Life Satisfaction: The Political Economy of Human Happiness. The American Political Science Review, 95(4): 939-952. URL http://dx.doi.org/10. 1017/S0003055400400110.

Rözer, J., and Kraaykamp, G. (2012). Income Inequality and Subjective Well-being: A CrossNational Study on the Conditional Effects of Individual and National Characteristics. Social Indicators Research, 113(3): 1009-1023. URL http://dx.doi.org/10.1007/s11205-012-0124-7.

Schneider, S. M. (2016). Income Inequality and Subjective Wellbeing: Trends, Challenges, and Research Directions. Journal of Happiness Studies, 17(4): 1719-1739. URL http://dx.doi.org/ 10.1007/s10902-015-9655-3.

Schyns, P. (2002). Wealth of Nations, Individual Income and Life Satisfaction in 42 Countries: A Multilevel Approach. Social Indicators Research, 60(1/3): 5-40.

Senik, C. (2004). When information dominates comparison: Learning from Russian subjective panel data. Journal of Public Economics, 88(9-10): 2099-2123. URL http://dx.doi.org/10.1016/ S0047-2727(03)00066-5.

Senik, C. (2005). Income distribution and well-being: what can we learn from subjective data? Journal of Economic Surveys, 19(1): 43-63. URL http://dx.doi.org/10.1111/j.0950-0804.2005. 00238.x.

Snijders, T. A. B., and Bosker, R. J. R. J. (1999). Multilevel analysis: an introduction to basic and advanced multilevel modeling. London: Sage Publications.

Stevenson, B., and Wolfers, J. (2008). Economic Growth and Subjective Well-Being: Reassessing the Easterlin Paradox. Brookings Papers on Economic Activity, 2008(Spring).

van Praag, B. M. S., and Ferrer-i-Carbonell, A. (2008). Happiness Quantified: A Satisfaction Calculus Approach. Oxford ; New York: Oxford University Press, revised edition.

Veenhoven, R. (2005). Return of Inequality in Modern Society? Test by Dispersion of LifeSatisfaction Across Time and Nations. Journal of Happiness Studies, 6(4): 457-487. URL http://dx.doi.org/10.1007/s10902-005-8858-4. 
Veenhoven, R., and Hagerty, M. (2006). Rising Happiness in Nations 1946-2004: A Reply to Easterlin. Social Indicators Research, 79(3): 421-436. URL http://dx.doi.org/10.1007/ s11205-005-5074-x.

Verme, P. (2011). Life Satisfaction and Income Inequality. Review of Income and Wealth, 57(1): 111-127. URL http://dx.doi.org/10.1111/j.1475-4991.2010.00420.x.

Wang, P., Pan, J., and Luo, Z. (2014). The Impact of Income Inequality on Individual Happiness: Evidence from China. Social Indicators Research, 121(2): 413-435. URL http://dx.doi.org/10. 1007/s11205-014-0651-5.

WVS (2016). World Values Survey Wave 6 2010-2014 Official Aggregate, v.20150418. World Values Survey Association. Aggregate File Producer: Asep/JDS. Madrid, Spain. 


\section{Economics}

Please note:

You are most sincerely encouraged to participate in the open assessment of this article. You can do so by either recommending the article or by posting your comments.

\section{Please go to:}

http://dx.doi.org/10.5018/economics-ejournal.ja.2018-43

The Editor 